\title{
THERMAL MANAGEMENT OF LED LUMINAIRES BASED ON COMPUTATIONAL FLUID DYNAMIC
}

\author{
Odirlan Iaronka, Vitor Cristiano Bender, Tiago Bandeira Marchesan \\ Electronic Ballast Research Group (GEDRE) - Federal University of Santa Maria (UFSM) \\ Santa Maria - RS, Brazil \\ e-mail: odirlan.ufsm@gmail.com
}

\begin{abstract}
Large LED (light-emitting diodes) clusters are currently designed to replace the lamps commonly used in parks, roadways, tunnels and street lighting. However, the success of these designs is heavily dependent on the performance of the thermal management. Thermal performance affects light extraction, reliability and lifetime of LED lamp. This paper proposes thermal management solutions to improve the design of LED luminaires. These solutions include natural convection and forced air convection into a closed cooling loop. The LED driver influence on luminaire heating is also evaluated in this paper. Simulations employing Finite-Volume Method (FVM) and Computational Fluid Dynamics (CFD) have been done to analyze the system's performance and to propose improvements in the airflow design. Comparisons of the experimental and simulation results are presented for validation purposes. ${ }^{1}$
\end{abstract}

Keywords - Computational Fluid Dynamic, Cooling System, Finite-Volume Method, Light Emitting Diode, Street Lighting, Thermal Management.

\section{INTRODUCTION}

Light-Emitting Diodes (LEDs) applied to street lighting are gaining much interest in the latest years. They can provide energy savings, good reliability and long lifetime $(50-100 \mathrm{kh})$, resulting in low upkeep costs for the lighting system [1]. Studies expect a reduction of around $42 \%$ of energy consumption with street lighting, from the year 2010 until 2030, by using the LED technology [2].

A significant issue for LEDs is the thermal management. The performance of a high-power LED strongly depends on the effectiveness of thermal management. A considerable portion of input LED energy is turned into heat (about 70 - $90 \%$ ). Therefore, an excessive increase in the LED junction temperature may lead to reliability problems such as low lighting efficiency, lifetime reduction, and even catastrophic failure [3]-[6].

For street lighting applications, the LED lamp thermal power dissipation is typically about 50 to $200 \mathrm{~W}$. Therefore, the luminaire structure should be built to ensure a sufficient heat transfer through their parts. Heat from the LED junction is conducted through the body structure and is transferred to the environment due to convection. To handle this heat transfer, a suitable surface area is necessary. Thus, most LED array have been developed using bulky heatsinks or active solutions with fans [7],[8].

Another important topic to be addressed is the heat generated by the LED driver on the entire luminaire design. The presence of the driver inside the luminaire may cause a significant increase on the LED junction temperature [9].

This paper proposes three thermal designs for a LED street lighting luminaire (LED SLL). Each thermal design presents distinct characteristics to handle heat generation and to control temperature. The heat transfer phenomena is investigated using Computational Fluid Dynamics (CFD) simulations employing the Finite-Volume Method (FVM) with a commercial software ANSYS CFX. The LED driver influence, when located inside of the luminaire, is also approached. Comparison among these three design approaches provides indicatives to better thermal management techniques in LED SLL. Finally, experimental results are carried out with infrared thermography to validate the simulation results.

The paper is organized as follows: Section II presents the main concepts about drivers for LED luminaires. Section III presents three thermal designs for LED luminaires. In Section IV, the FVM model for all luminaire components is presented. Section V explains about CFD simulation and shows the simulations results. The Section VI shows experimental results and Section VII presents the main conclusions of this work.

\section{DRIVERS FOR LED LUMINAIRES}

LEDs are unable to regulate their own current if they are supplied by voltage sources. Therefore, LED drivers are the electronic circuits which intend to control the forward current of LEDs [10]. For street lighting applications, some characteristics are important for LED drivers, such as: high power factor, low harmonic distortion, long lifetime and reliability.

The international standard IEC 61000-3-2 Class C presents the requirements for power factor and harmonic content for LED drivers. The IEC 61347-2-3 specifies particular requirements for electronic control of LED modules [11][12]. The long lifetime and reliability of LED driver is an important topic of research and many techniques for increase the LED driver lifetime have been proposed, such as: storage capacitance elimination or minimization, converter integration and photometrical analysis [13]-[18]. 
The LED electrothermal characteristics make the driver implementation a hard design task, because when the driver is placed inside the LED SLL without any thermal management, an increase in LED junction temperature occurs. This fact causes voltage drop across the device. For a given current, the voltage drop is of order of $\mathrm{mV} /{ }^{\circ} \mathrm{C}$. This dynamic behavior affects the LED driver design, as the continuous drop in LED voltage (due to temperature increase) causes an increase in the LED current, yielding a positive feedback behavior that should be considered in driver design [19]. The junction temperature increase may lead to light output decay and lifetime reduction or, in worst cases, catastrophic failure of the LED device

In this paper, the Buck-Boost converter has been chosen as the LED driver. It provides high input power factor working in discontinuous conduction mode to the full range of the input voltage. The objective is to evaluate the thermal influence of this converter on luminaire thermal performance. Characteristics of the converter design are be obtained in [20].

\section{THERMAL MANAGEMENT OF LED LUMINAIRES}

To enhance the thermal dissipation, three distinct thermal designs for a LED SLL are proposed. For this, a luminaire for street lighting application should have a robust structure with degrees of protection provided by ANSI/IEC 60529 standard. A minimum rating of IP65 is desired for the LED module and the electrical assembly is rated of a protection level of IP54 [21]-[23].

In order to be in accordance with established standards, two designs for the proposed luminaire were considered with a closed cooling system (CCS). The overall and exploded view of the proposed LED SLL are shown in Figures 1 and 2 , respectively. The most important parts of the luminaire are:

1) LED driver compartment;

3) Mechanical connection of luminaire;

5) Heatsink;

9) Fans compartment;

13) Air duct to heatsink.

The other components are part of the construction of the luminaire, such as covers, fasteners and others.

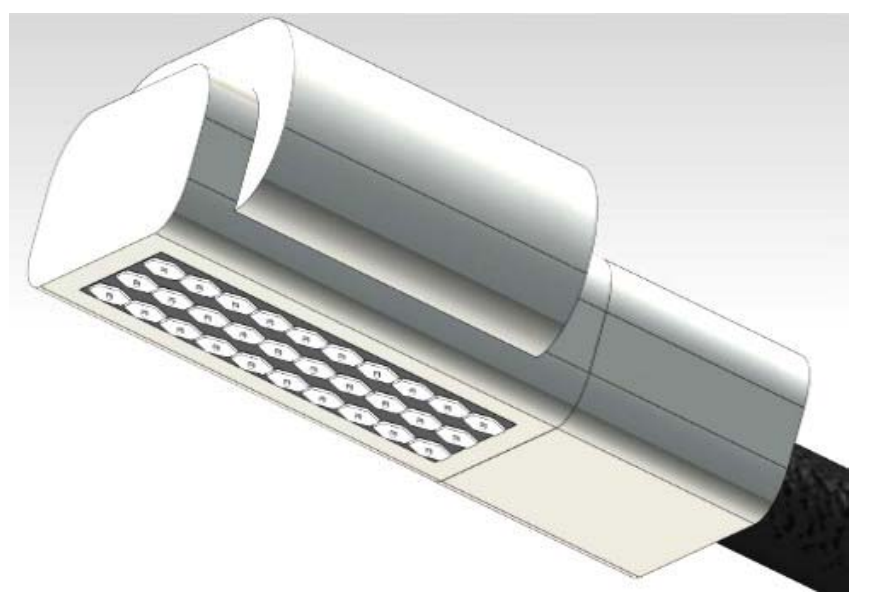

Fig. 1. Overall luminaire view.

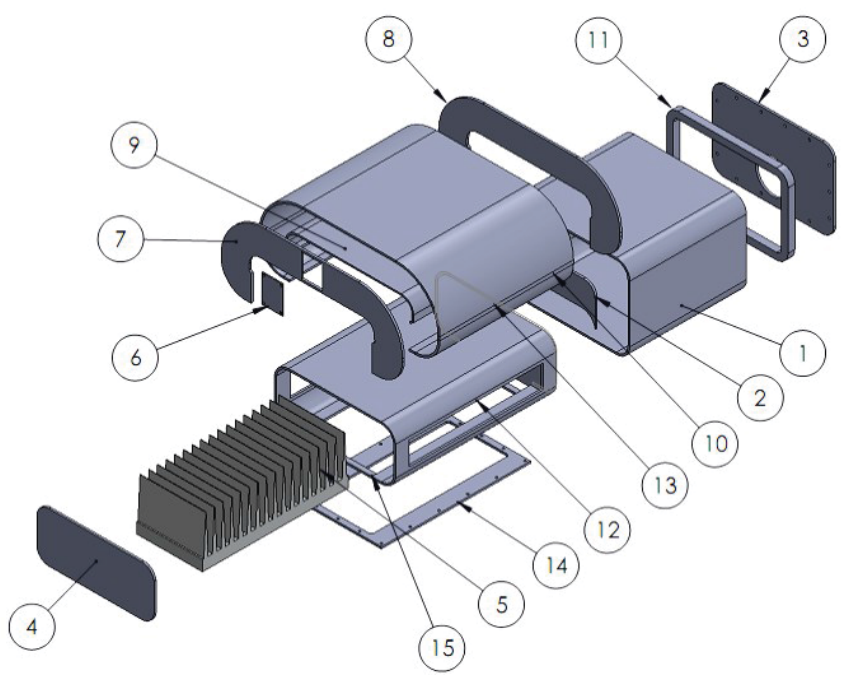

1. Electrical compartment

2. Back duct cover

3. Back cover

4. Front cover

5. Heatsink

6. Coolers cover

7. Front duct cover

8. Back duct cover

9. Bottom duct surface (coolers compartment) 10. Upper duct surface

11. Back strengthening structure

12. Heatsink compartment

13. Back heatsink compartment cover

14. Bottom cover

15. Complement

Fig. 2. Luminaire exploded view.

\section{A. Design A}

The design A of the LED SLL consists in arranging the LED devices on the heatsink, as shown in Figure 3. In that model the external environment has direct contact with the heatsink fins, without protective cover for the LEDs and heatsink.

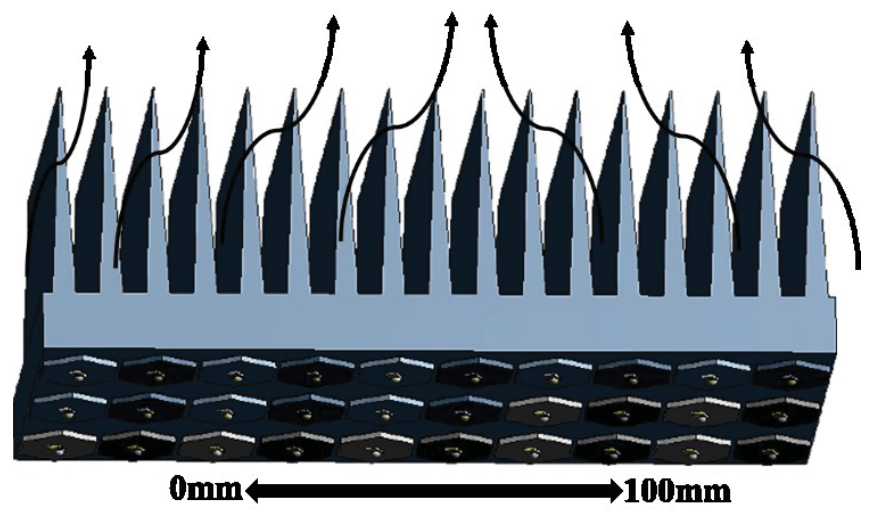

Fig. 3. Design A - LEDs mounted on the heatsink with the natural convection.

In this way, the heat from LEDs is conducted to the heatsink and after to the environment by natural convection. The heat transfer occurs by conduction from the LED junction to the heatsink. After this, the natural convection is the responsible by the heat dissipation of heatsink to environment. This assembly is simple and low cost. However, this method of assembly is not in accordance to the minimum desired protection rating (IP 65), because the heatsink fins are exposed to the environment, without protection for dust and water. Besides the dust and water, other particles can damage the heatsink fins and the electrical parts of the luminaire. This assembly is not for the final application, and it was developed only for laboratory study. 


\section{B. Design B}

In order to obtain the protection degree in accordance with standards (IP65), the structure of the luminaire, composed of LEDs, heatsink and electric driver, should be enclosed. However, when the luminaire structure was closed with a body, the natural convection is hindered in the heatsink fins. Therefore, a solution is to provide a forced convection using cooling fans, increasing the air velocity and consequently the heat exchange, as shown in the designs $\mathrm{B}$ and $\mathrm{C}$.

Without external visible fins, it is possible to avoid the deposition of dust and birds excretion, which cause losses in the cooling system efficiency. When the airflow is confined in a closed duct, an increase in air friction with the internal duct walls improves the thermal flow, reducing the thermal resistance [24][25].

The proposed design B is shown in Figure 4. The cooling is performed by five fans, a finned heatsink and an air duct. The airflow velocity is increased by the fans and circulates in parallel with heatsink fins (as show the arrows in Figure 4). The heat exchange is done with forced convection between the heatsink and the inner luminaire surface. The natural convection occurs between external luminaire surface and the environment.

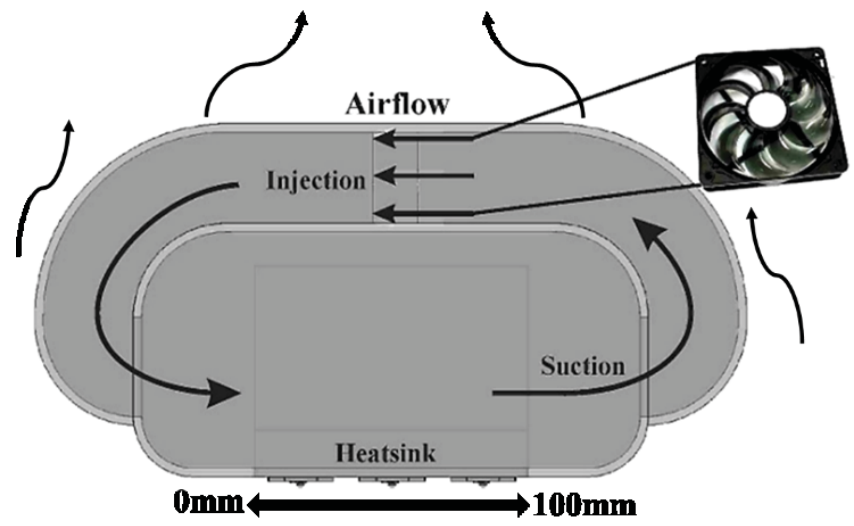

Fig. 4. Design B - CCS operation with parallel airflow and natural convection.

\section{Design $C$}

In order to verify the air flow direction influence, a luminaire with airflow perpendicular with the heatsink was studied, as shown in Figure 5.

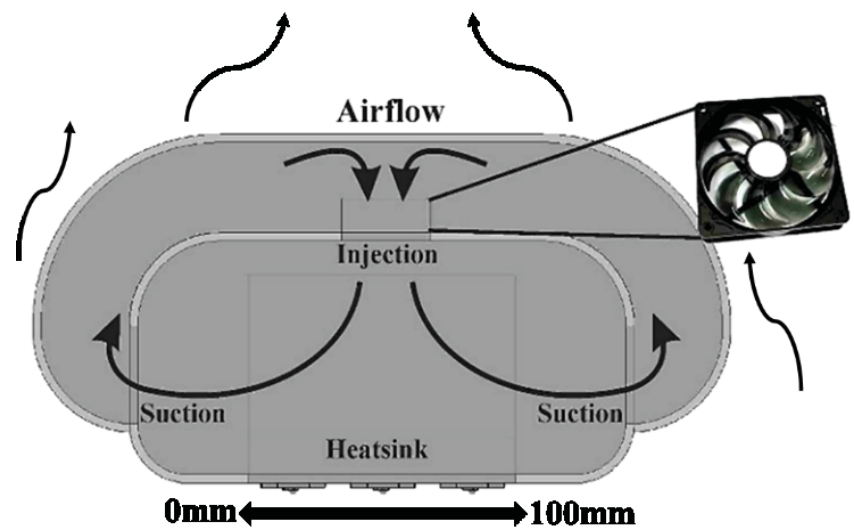

Fig. 5. Design C - CCS operation with perpendicular airflow and natural convection.
In this model the fans are on top of the luminaire, injecting air on heatsink (as may be observed in Figure 5). The only change, in relation to design $\mathrm{B}$, is the position of the fans. The characteristics of the other parts are not changed.

When the air flow direction is modified and the air flow is not aligned with fins, an increase in the airflow velocity and turbulence takes place into the luminaire. This fact increase the air friction with luminaire walls, which improve the heat transfer and then reducing LED junction temperature.

\section{LED LUMINAIRES ANALYSIS USING THE FINITE VOLUME METHOD}

A model to represent the LED luminaires have been developed using the FVM. The FVM consists on a subdivision of a continuum volumetric body, transforming the single body (one piece body) into a discretize body structure, formed by linked finite-volumes that keep the same properties of the original body, these finite-volume are named mesh. The finite-volumes of each body discretized are described by differential equations, based in the theoretical principle of FVM, presented with details in [26].

In order to handle the fluid dynamic problem, the simulation software solve a set of Navier-Stokes equations. For example, the continuity equation, given by (1). Where, $t$ is time, $\rho$ is the density, $U$ is the fluid velocity, $\nabla$ is the del operator, which represents an one-dimensional domain. The other equations solved by the software can be found in [27].

$$
\frac{\partial \rho}{\partial t}+\nabla(\rho U)=0
$$

For all proposed luminaire designs, the mesh was refined to obtain converged results. Several mesh refinements have been made until get the mesh independence. The numerical results presented in the following sections are those on the finest mesh, ensuring accuracy of results without compromising analysis time. All simulations were started from the same initial condition. The simulations were performed until the residuals results of equations for mass, momentum and energy were less than $1.10^{-6}$.

The commercial software ANSYS code CFX v15 was used for temperature distribution analysis in the luminaire. A study of fluid motion (fluid dynamics) was performed using the CFD ANSYS tools in steady-state. The solver module of the software ANSYS code CFX determined the equations order and the method utilized for resolution of these equations. The procedure adopted in this analysis will be explained as follows.

\section{A. LED FVM Model}

The model of the evaluated LED was the Philips Luxeon Rebel LEDs LXML-PWC1 [28]. The luminaire is composed of 30 LEDs (2.3W, each LED), mounted on a star printed circuit board (PCB). The LED dimensions are $2.93 \mathrm{~mm} \times 4.37 \mathrm{~mm} \times 1.85 \mathrm{~mm}$, as shown in Figure 6 .

\section{B. Driver FVM Model}

The LED driver mesh model was based on Buck-Boost converter and simplified considering only components that represent the major circuit power losses: magnetic cores, auxiliary sources and switches. A driver efficiency equal to 
$91 \%$ was considered and the power losses have been distributed in components according to its operation conditions. The overall power loss on the LED driver was 10 $\mathrm{W}$. The simulated model of the LED driver is shown in Figure 7.

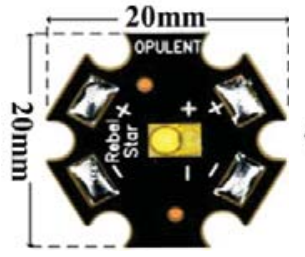

(a)

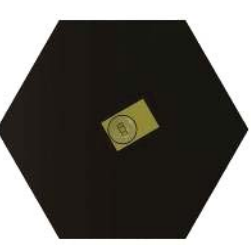

(b)

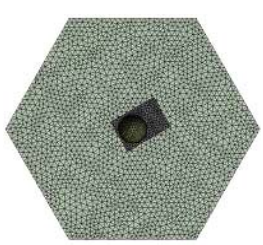

(c)
Fig. 6. (a) Philips ${ }^{\circledR}$ Luxeon Rebel LXML-PWC1 with star MCB. (b) FVM model. (c) Mesh of FVM Model.

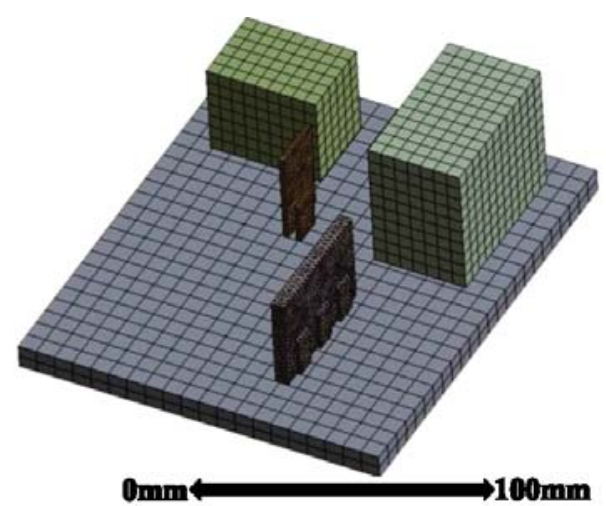

Fig. 7. LED driver (Buck-Boost) simplified model.

\section{Design A FVM Model}

LED packages were disposed on an aluminum heatsink using a Bond Ply $100^{\circledR}$ thermal adhesive to enhance the thermal contact [29]. The heatsink have a natural thermal resistance of $0.8^{\circ} \mathrm{C} / \mathrm{W}$ and is composed by 17 fins with $100 \mathrm{~mm}$ (width), as sketched in Figure 8. The heatsink thermal resistance was calculated based on the procedure presented in [30][31].

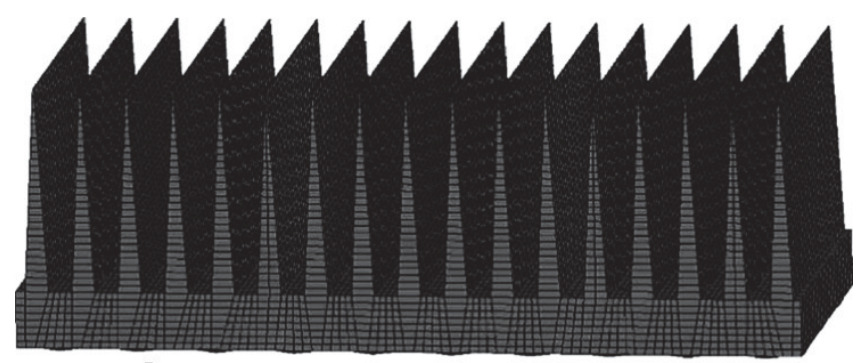

0mm $\longrightarrow \mathbf{1 0 0 m m}$

Fig. 8. Aluminium Heatsink mesh model.

\section{Design B and Design C FVM Model}

The luminaire body is fully built in aluminum, with emissivity 0.7 and thickness of $2 \mathrm{~mm}$. The simulated mesh model of the luminaire body is shown in Figure 9.

For CFD simulations, some assumptions in finite-volume model were considered, as follows:

a. The 3D design considers the original characteristics of all components; b. Some simplifications in the design of the luminaire body and driver have been done to decrease the computational cost and time;

c. A perfect bonding was considered between each material interfaces;

d. The emissivity of the luminaire was defined according to the material employed;

e. An amount of $85 \%$ of LED input power is turn into heat and it is applied to the LED junction $(58 \mathrm{~W})$;

f. The ambient and system initial temperature was set $30^{\circ} \mathrm{C}$ and $25^{\circ} \mathrm{C}$, respectively;

g. The airflow was adopted with velocity of $0.59 \mathrm{~m} / \mathrm{s}$;

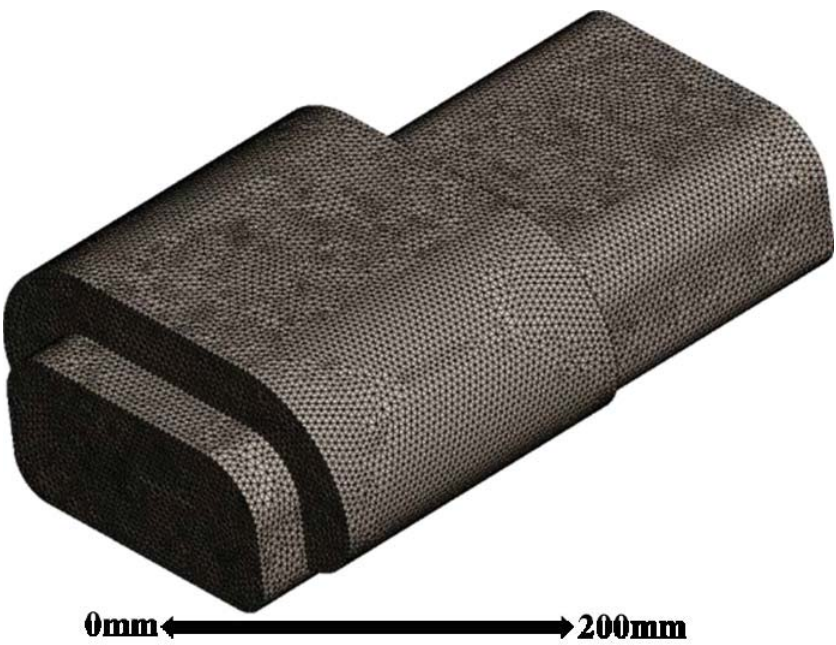

Fig. 9. Luminaire body FVM model.

Simulation results were performed in accordance to the following order: 1) The analysis with LEDs on the heatsink; 2) The analysis with CCS, with parallel airflow (design B) and perpendicular airflow (design C); 3) The LED junction thermal performance; 4) The driver influence inside of luminaire.

\section{SIMULATION RESULTS}

An unstructured tetrahedral mesh with prismatic near wall elements was generated automatically by Ansys software. The resulting mesh was composed of $3.5 \mathrm{M}$ elements. The simulations were performed using parallel local processing HP-MPICH. CFX Solver was run on a computer with 6-core Intel Xeon X5500 series with $2.5 \mathrm{GHz}$ processors and a RAM memory of $24 \mathrm{~Gb}$, were performed using the upwind numerical scheme (first order). A root mean square (RMS) residual target value of $1.10^{-6}$ was defined as the convergence criteria for the double precision simulation. Automatic time step was selected according to the analysis. Typical computation time for each case was about 24 hours.

\section{A. Design $A$}

In design A the thermal behavior of the heatsink with natural convection was analyzed. In this system, the heat generated in the LED junction is dissipated to the environment by heatsink. Figure 10 shows the gradient of the heatsink and LEDs temperature. The largest temperature was $82.77^{\circ} \mathrm{C}$ at LED junction. 


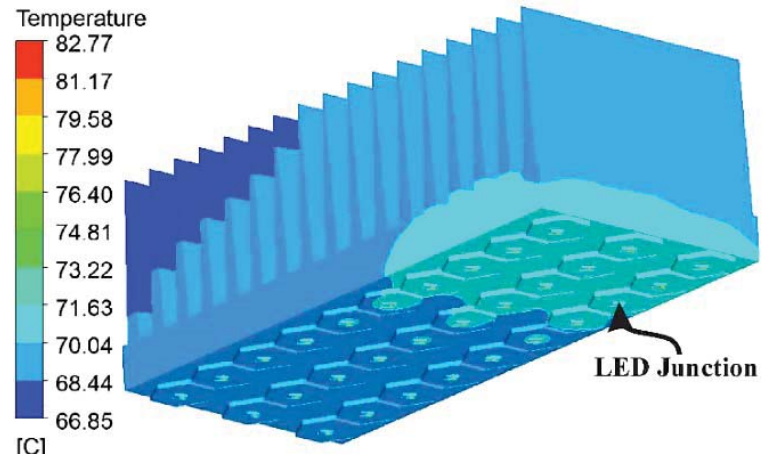

Fig. 10. Design A - Heatsink temperature with natural convection.

\section{B. Design $B$}

In design $B$ the forced air is the responsible for the heat transfer from the heatsink to the luminaire body. Therefore, the natural convection cools the body of the luminaire. The thermal exchange is increased with the increment of the velocity.

In the parallel airflow, the fans inject air parallels to the heatsink fins, as shown in Figure 11. The temperature of the luminaire is shown in Figure 12. The temperature is lower on the left side (cold air) and higher in the right side, due to the heating of the air when passing through the heatsink.

The internal temperature is better visualized in Figure 13, where the internal air temperature of the design $\mathrm{B}$ is presented.

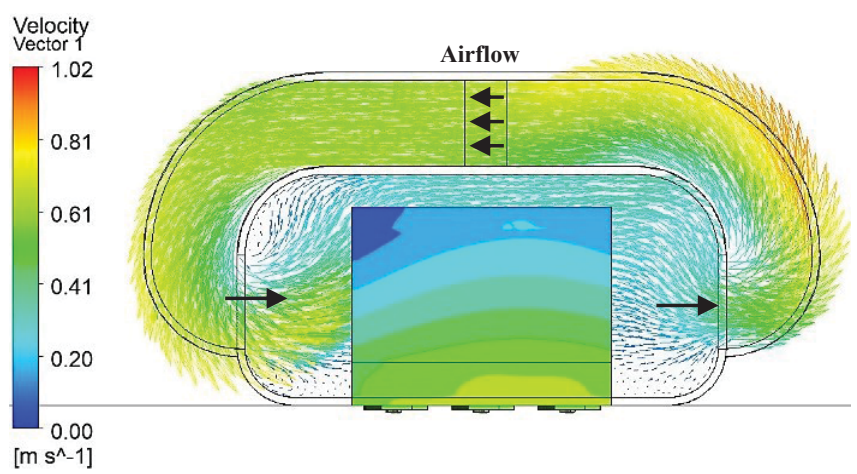

Fig. 11. Design B - Air velocity inside of luminaire.

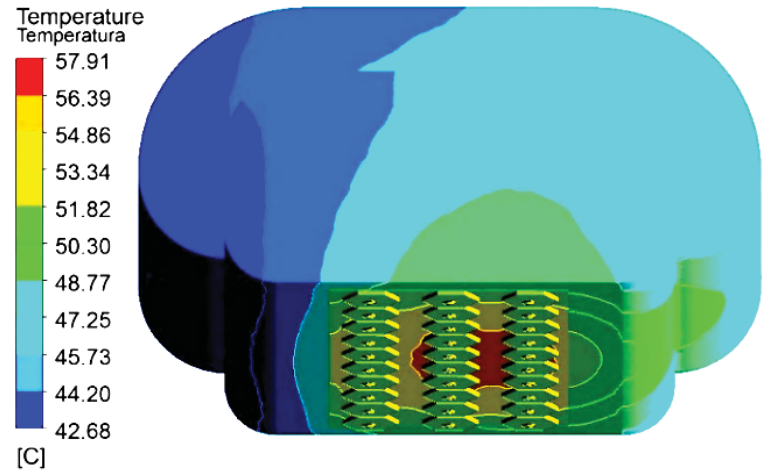

Fig. 12. Design B - External luminaire temperature.

\section{Design $C$}

In the perpendicular airflow, design $C$, the fans inject air over the heatsink, as shown in Figure 14. In this figure, the air velocity inside of luminaire can be observed. This structure presents more air movement and internal air swirling than structure of design $\mathrm{B}$. This fact causes a reduction in the heatsink temperature and a more uniformity distribution in the LED junction temperature, as shown in Figure 15. Consequently, the air temperature inside of the luminaire is decreased, as shown in Figure 16.

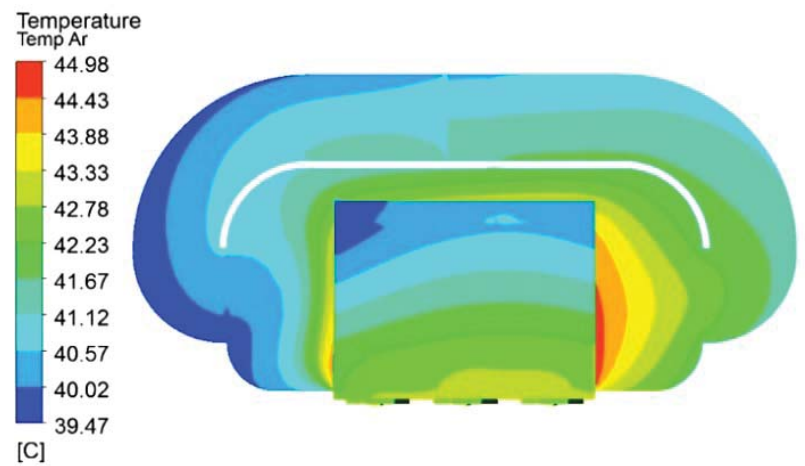

Fig. 13. Design B - Air temperature inside of luminaire.

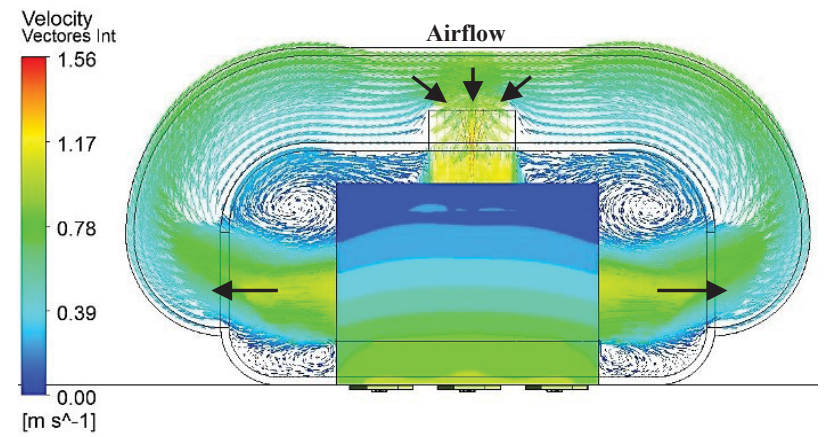

Fig. 14. Design C - Air velocity inside of luminaire.

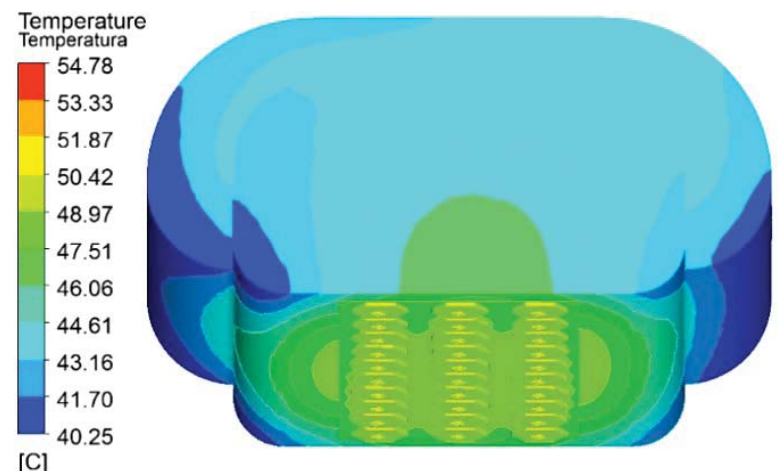

Fig. 15. Design $\mathrm{C}-$ External luminaire temperature.

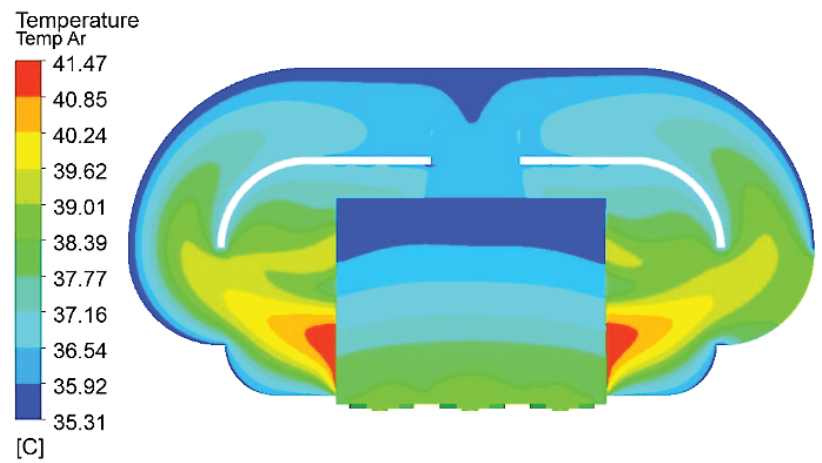

Fig. 16. Design $\mathrm{C}-$ Air temperature inside of luminaire. 


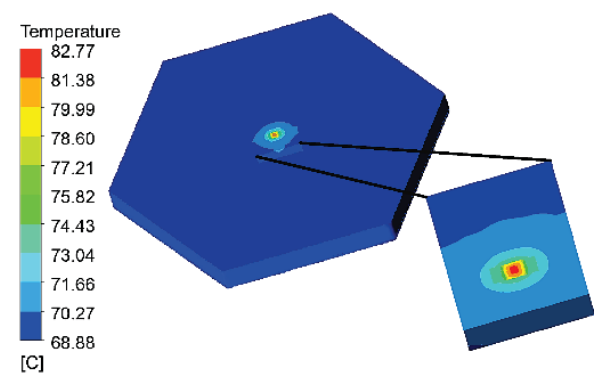

Fig. 17. Design A - Junction temperature.

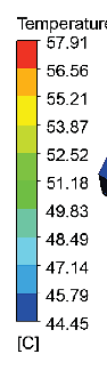

Fig. 18. Design B - Junction temperature.

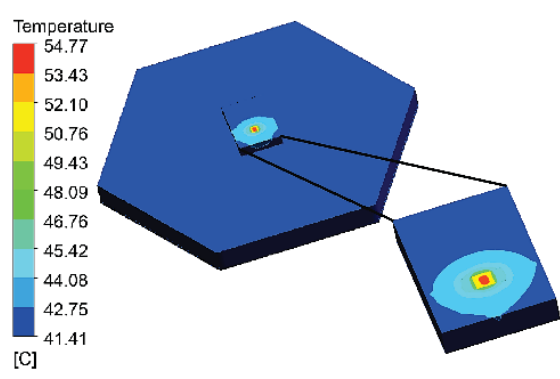

Fig. 19. Design C - Junction temperature.

\section{Junction Temperature in each LED}

The LED junction temperature defines the system luminous flux. In the Figures 17, 18 and 19 the detailed junction temperatures for the three proposed designs are presented. The LEDs shown in the figures were those with the temperature close to the average of the whole set.

The design B (Figure 18) and design C (Figure 19) present lower LED junction temperature in comparison to design $\mathrm{A}$ (Figure 17). The junction temperature reduction is approximately $32 \%$, causing an increment of $5 \%$ in luminous flux.

The uniformity in the junction temperature of each LED is important as it ensures the same luminous flux for each LED that composes the luminaire. In Figure 20 a comparison between design $\mathrm{B}$ and $\mathrm{C}$ is presented showing the temperature uniformity distribution in each case.

Observing Figure 20 it is perceived that the design B has the largest junction temperatures and has not a uniform temperature distribution. This fact affect the lifetime of each LED in a different manner. In design $\mathrm{C}$ a decrease and more uniform junction temperature was obtained. The design $\mathrm{C}$ provides an increase of $2.5 \%$ in luminous flux compared to design $\mathrm{B}$.

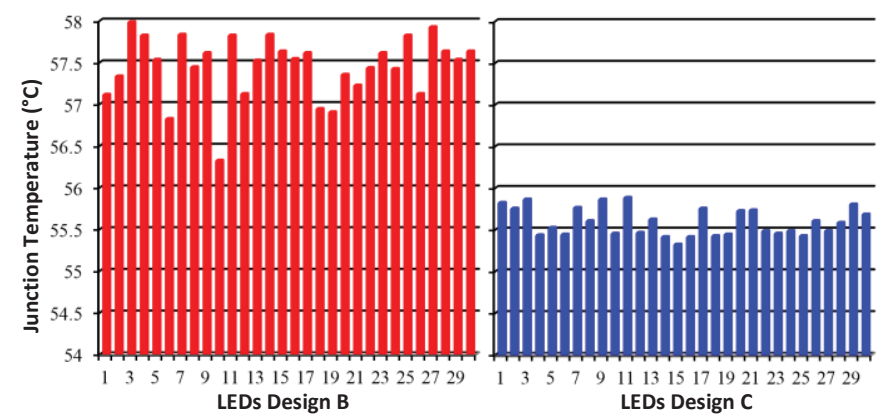

Fig. 20. Temperature of each LED of the Design B and C.

\section{E. Driver thermal Influence in Luminaire}

The LED power is responsible for the most part of generated heat. However, the heat generated in the LED driver has influence in the global system temperature. In this section, the impact of the driver on the thermal behavior of the luminaire is evaluated. The procedure consists in to analyze the temperature of the luminaire in both conditions, with and without the driver presence. Figure 21 shows the comparison in both cases.

The difference of temperature in steady state has been obtained through simulation results to determine the temperature increments in LED devices, as shown in Figure 22. Results presented in Figure 23 show an increase in the average temperature of $2.45^{\circ} \mathrm{C}$ for the LED junction and $3.63^{\circ} \mathrm{C}$ for the heatsink temperature when the driver losses were considered.

In addition, the LED driver components are not submitted to the forced air convection. This fact is observed in Figure 24, where the largest temperature is in the Buck-Boost main switch $\left(77.84^{\circ} \mathrm{C}\right)$. The luminous flux performance has a $3 \%$ of reduction due to the presence of the driver inside the luminaire.

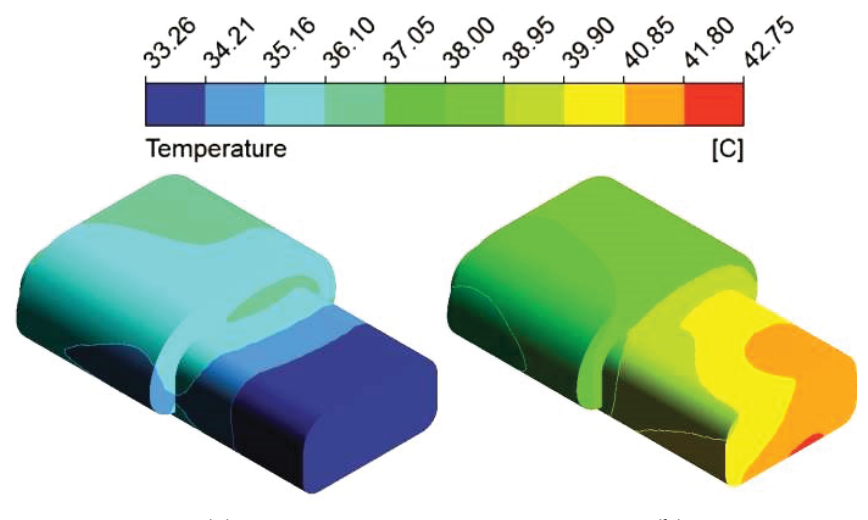

(a)

(b)

Fig. 21. Luminaire temperature (a) without LED driver (b) with LED driver.
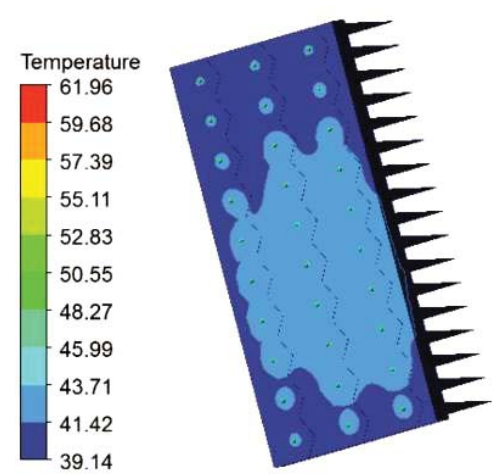

(a)

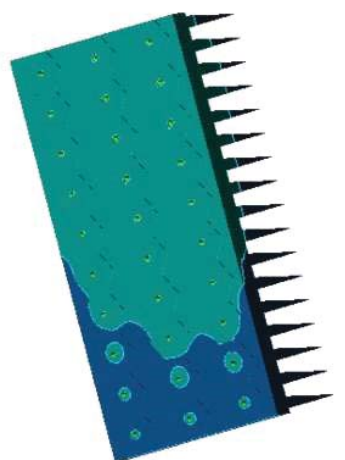

(b)
Fig. 22. Luminaire with CCS: LED temperature (a) without LED driver (b) with LED driver. 


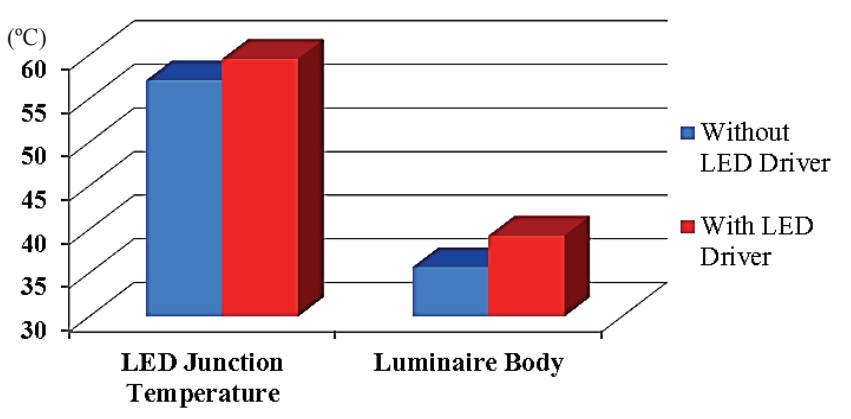

Fig. 23. Average temperature of systems.

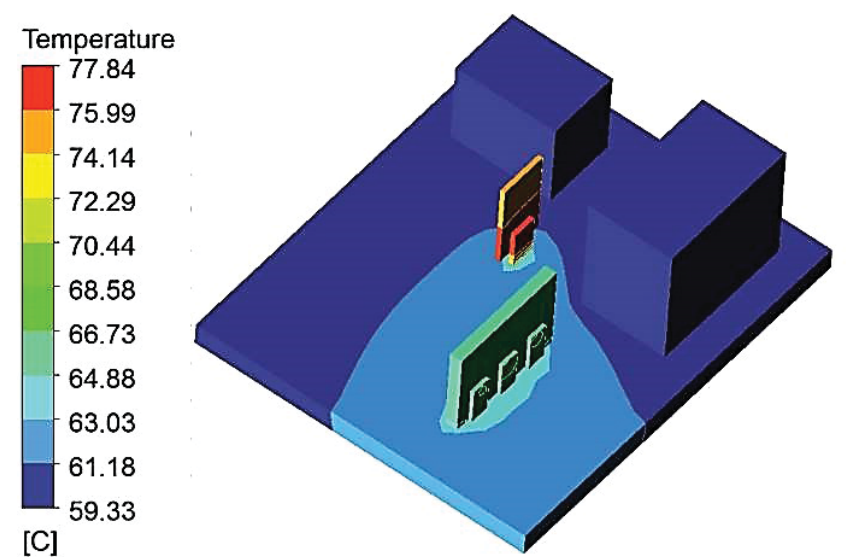

Fig. 24. The highest temperature of the luminaire driver is in the circuit switch.

\section{EXPERIMENTAL RESULTS}

A luminaire prototype has been developed. Two designs were built for comparison: design A, as shown in Figure 25 and design B, with parallel airflow, as shown in Figure 26. Although, the simulation results indicate a better performance with Design $\mathrm{C}$, due to mechanical and constructive difficulties, it could not be implemented in the laboratory. The prototype was built using polished aluminum. The fans (coolers) have been placed in the top region of the luminaire for Design $\mathrm{B}$.

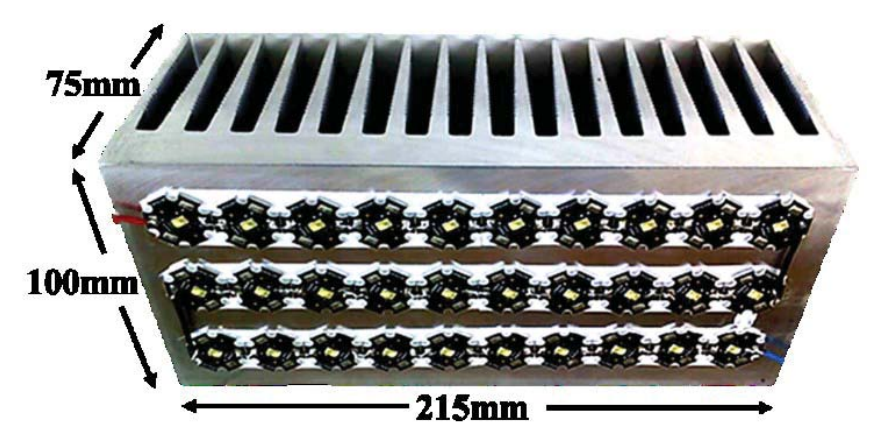

Fig. 25. Design A - LED Street Lighting Luminaire prototype photography (LEDs and heatsink).

The designed LED luminaire operates in the rated conditions, with LED forward current of $700 \mathrm{~mA}$ (total electrical power $67 \mathrm{~W}$ ). The temperature measurement was performed using a Thermal Imager Fluke Ti32. This equipment has a temperature range of $-20{ }^{\circ} \mathrm{C}$ to $+600{ }^{\circ} \mathrm{C}$ and has a temperature accuracy of $\pm 2{ }^{\circ} \mathrm{C}$ or $2 \%$. All temperature measurement was obtained after the LED luminaire reaches the steady-state.

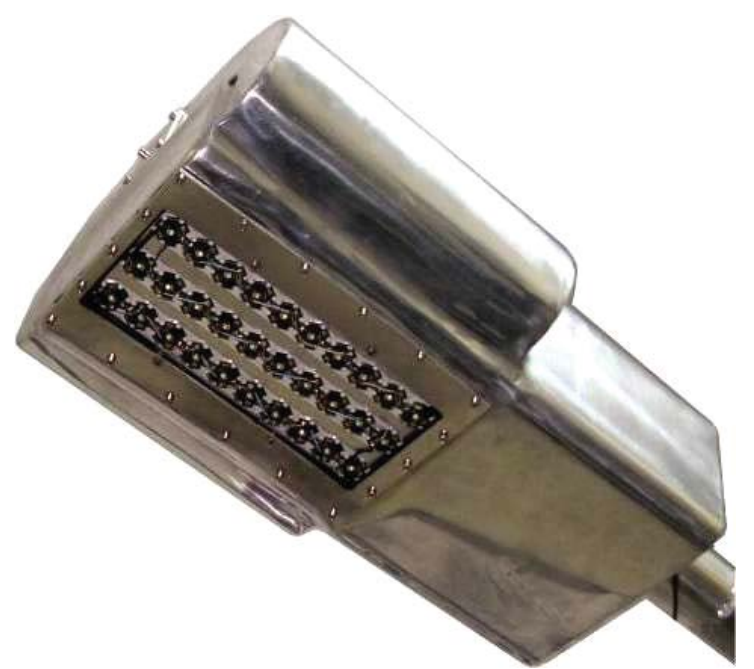

Fig. 26. LED Street Lighting Luminaire prototype photography.

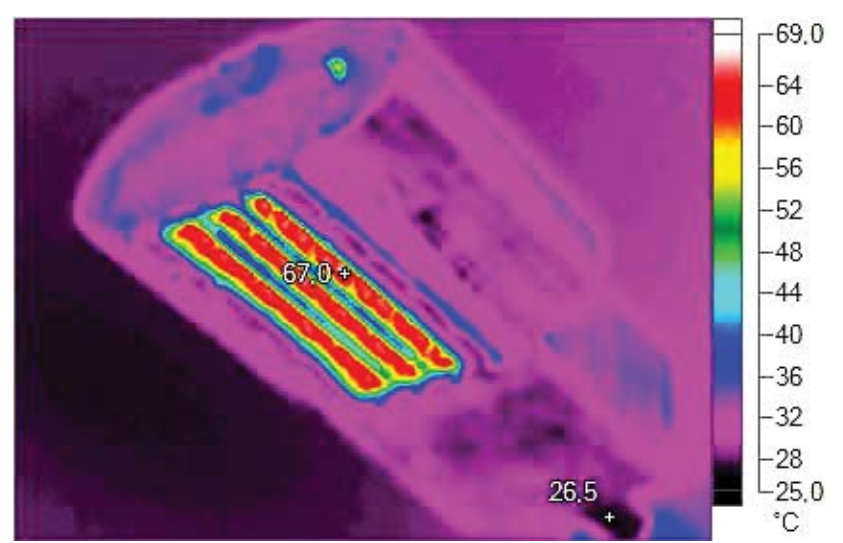

(a)

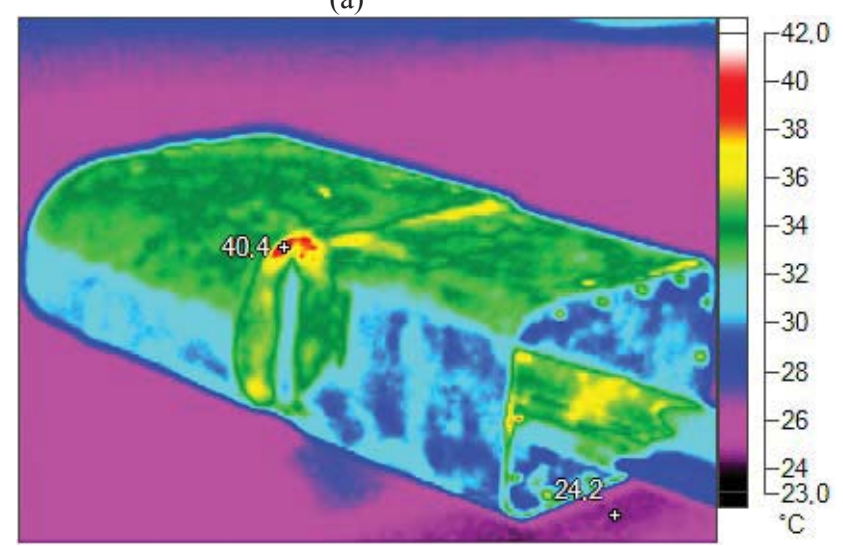

(b)

Fig. 27. Infrared thermography result with LED driver (a) LED detail (b) Luminaire Detail.

Although the thermal image does not represents the real junction temperature, because it presents only the LED surface temperature, the value presented by measurements was considered as an estimative to calculate the error between experimental and simulation results. The relative error between simulation and experimental results in LED 
junction temperature was $7.52 \%$ for design $B$. The luminaire infrared results are shown in Figure 27.

The error is justified by several factors, such as, equipment measurement accuracy, material characteristics and model simplification.

Photography of the LED driver (Buck-Boost) is shown in Figure 28 and LED driver infrared result in Figure 29. In the LED driver, the error at the hot spot (main switch) between simulation and experimental result was $8.63 \%$.

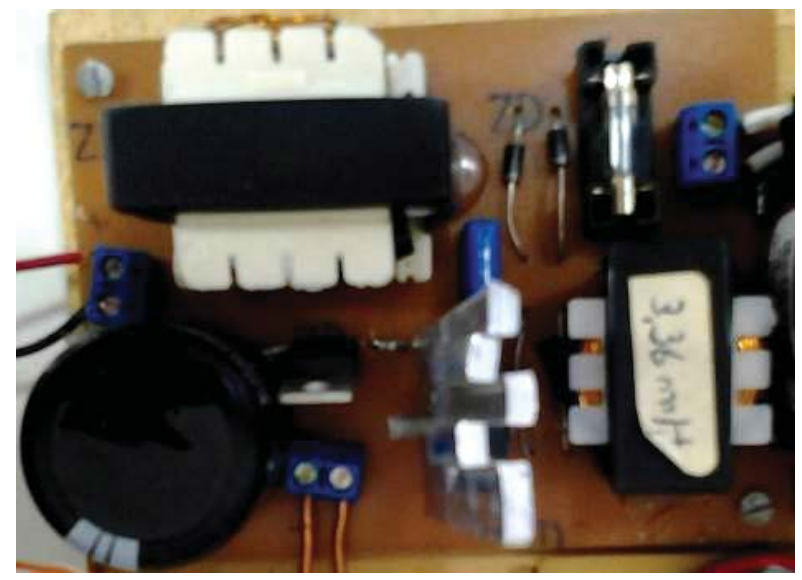

Fig. 28. Photography of Buck-Boost converter.

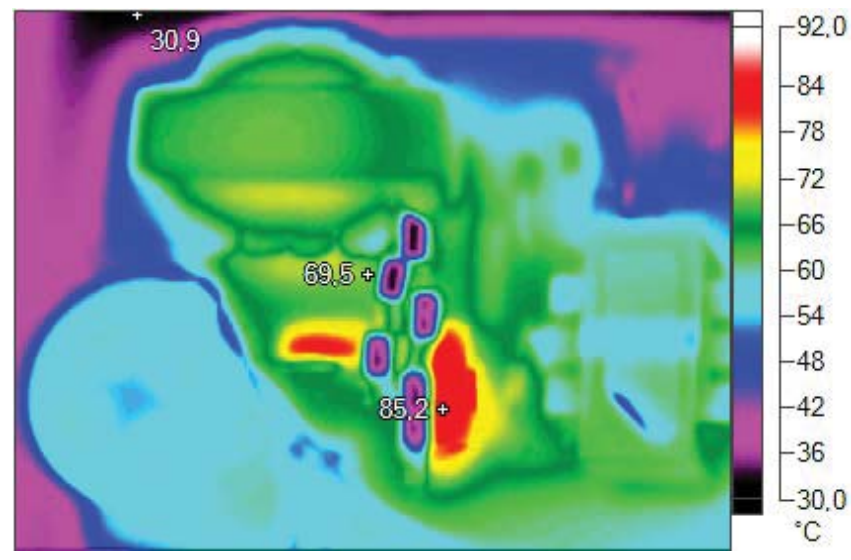

Fig. 29. Infrared thermography result of LED Driver.

\section{CONCLUSION}

Thermal management is very important to the development of LED lighting systems. The approach presented is useful to predict the temperature operation of LED luminaires. A mechanical and thermal structure with a CCS was proposed to decrease the LED junction temperature enhancing its luminous flux and lifetime. The influence of the LED driver losses was also analyzed.

A LED luminaire and a LED driver have been modelled and simulated using CFD. The small error between simulation and experimental results presents the CFD analyses as a good tool for LED thermal design verifications.

The CCS provides a lower and good uniformity of the junction temperature with an increase of $5 \%$ in luminous flux. Furthermore, the design of this luminaire is in agreement with IESNA LM80 and ANSI/IEC 60529 luminaire standards.

Future works can present other structures for improving the airflow path and, in addition, developing a method for reducing the driver effect on the LED junction temperature.

\section{ACKNOWLEDGEMENT}

The authors would like thank Federal University of Santa Maria, CAPES, CNPq (proc 4732002011-2) and the Brazilian Government for all financial support on this work.

\section{REFERENCES}

[1] Philips Lumileds, "White Paper: Street Lighting LEDs: Coming Soon to a Street Light Near You", 2008.

[2] United States Department of Energy, "Solid-State Lighting Research and Development: Multi-Year Program Plan", 2012.

[3] Q. Yaxiao, L. Deyan, S. Y. Hui, "A Simple Method for Comparative Study on the Thermal Performance of LEDs and Fluorescent Lamps", IEEE Trans. on Power Electronics, vol. 24, pp. 1811-1818, Jul. 2009.

[4] H. T. Chen, X. H. Tao, S. Y. R. Hui, "Estimation of Optical Power and Heat-Dissipation Coefficient for the Photo-Electro-Thermal Theory for LED Systems", IEEE Trans. on Power Electronics, vol. 27, pp. 21762183, Apr. 2012.

[5] M. Y. Tsai, C. H. Chen, C. S. Kang, "Thermal analyses and measurements of low-Cost COP package for highpower LED", in 58th Electronic Components and Technology Conference, pp. 1812-1818, 2008.

[6] J. P. You, Y. He, F. G. Shi, "Thermal management of high power LEDs: Impact of die attach materials", in International Microsystems, Packaging, Assembly and Circuits Technology, pp. 239-242, 2007.

[7] J. Petroski, J. Norley, J. Schober, B. Reis, R. A. Reynolds, "Conduction cooling of large LED array systems", in 12th IEEE Intersociety Conf. on Thermal and Thermomechanical Phenomena in Electronic Systems, pp. 1-10, 2010.

[8] L. Sheng, L. Tim, L. Xiaobing, C. Mingxiang, J. Xiaoping, "A microjet array cooling system for thermal management of active radars and high-brightness LEDs", in Electronic Components and Technology Conference, p. 5, 2006.

[9] X. Perpina, R. J. Werkhoven, M. Vellvehi, J. Jakovenko, X. Jorda, J. M. G. Kunen, P. Bancken, P. J. Bolt, "Thermal Analysis of LED Lamps for Optimal Driver Integration", IEEE Trans. on Power Electronics, vol. 30, pp. 3876-3891, Jul. 2015.

[10] G. Sauerlander, D. Hente, H. Radermacher, E. Waffenschmidt, J. Jacobs, "Driver Electronics for LEDs", in 41st IEEE Industry Applications Conf., pp. 2621-2626, 2006.

[11] IEC61000-3-2, "Electromagnetic compatibility (EMC) Part 3-2: Limits - Limits for harmonic current emissions (equipment input current $\leq 16$ A per phase)", 2009.

[12] IEC61347-2-13, "Lamp controlgear - Part 2-13: Particular requirements for d.c. or a.c. supplied electronic controlgear for LED modules", 2006. 
[13] M. Arias, D. G. Lamar, J. Sebastian, D. Balocco, A. A. Diallo, "High-Efficiency LED Driver Without Electrolytic Capacitor for Street Lighting", IEEE Trans. on Industry Applications, vol. 49, pp. 127-137, Jan-Feb. 2013.

[14] P. S. Almeida, M. S. Soares, H. A. C. Braga. "Storage Capacitance Minimization in LED drivers based on photometrical constraints and converter integration". Eletrônica de Potência. pp. 962-971, mar./mai. 2013.

[15] D. Camponogara, D. R. Vargas, M. A. Dalla Costa, A. Campos, T. B. Marchesan, J. M. Alonso. "Minimização de Capacitâncias de luminárias a LED baseadana conexão otimizada de conversores estáticos". Eletrônica de Potência. pp. 1001-1009, mar./mai., 2013.

[16] J. M. Alonso, D. Gacio, A. J. Calleja, F. Sichirollo, M. F. da Silva, M. A. D. Costa, R. N. do Prado, "Reducing storage capacitance in off-line LED power supplies by using integrated converters", in IEEE Industry Applications Society Annual Meeting, pp. 1-8, 2012.

[17] V. C. Bender, N. D. Barth, G. C. Flores, M. A. Dalla Costa, T. B. Marchesan, P. S. Almeida, H. A. C. Braga, "Electrothermal Methodology Applied to Flicker Analysis in Off-line LED Systems " in 39th Annual Conf. on IEEE Industrial Electronics Society, pp. 60506055, 2013.

[18] P. S. Almeida, F. J. Nogueira, L. Guedes, H. A. C. Braga, "An experimental study on the photometrical impacts of several current waveforms on power white LEDs", in Brazilian Power Electronics Conference, pp. 728-733, 2011.

[19] D. Gacio, J. M. Alonso, J. Garcia, M. S. Perdigao, E. S. Saraiva, F. E. Bisogno, "Effects of the Junction Temperature on the Dynamic Resistance of White LEDs", IEEE Trans. on Industry Applications, vol. 49, pp. 750-760, Mar. 2013.

[20] R. A. Pinto, M. R. Cosetin, T. E. Bolzan, T. B. Marchesan, A. Campos, J. M. Alonso, M. A. Dalla Costa, R. N. do Prado, "A bidirectional buck-boost converter to supply LEDs from batteries during Peak Load Time", in 37th Annual Conference on IEEE Industrial Electronics Society, pp. 2848-2853, 2011.

[21] IEC60529, "Degrees of protection provided by enclosures (IP Code)", ed, 2001.

[22] ANSI-C136.25, "American National Standard for Roadway and Area Lighting Equipment - Ingress Protection (Resistance to Dust, Solid Objects and Moisture) for Luminaire Enclosures", 2009.

[23] ANSI-C136.37, "American National Standard for Roadway and Area Lighting Equipment Solid State Light Sources Used in Roadway and Area Lighting", 2011.

[24] F. M. Kreith, R.; Bohn, M., Principles of Heat Transfer, 7th ed. Stamford: Cengage Learning, 2011.

[25] S. Prstic, A. Bar-Cohen, "Heat shield an enhancement device for an unshrouded, forced convection heat sink", in The Ninth Intersociety Conference on Thermal and Thermomechanical Phenomena in Electronic Systems, pp. 319-324, 2004.
[26] R. Eymard, T. Gallou, R. Herbin, "Finite Volume Methods: Handbook for Numerical Analysis", Ph. Ciarlet J.L. Lions eds, Marseille, pp 713-1020, 1997.

[27] ANSYS. ANSYS CFX-Solver Theory Guide. Available:http://148.204.81.206/Ansys/150/ANSYS\%2 0CFX-Solver\%20Theory\%20Guide.pdf

[28] Philips Lumileds, Technical Datasheet DS64, 2011.

[29] BERGQUIST. Bond Ply 100 Datasheet. Available: http://www.bergquistcompany.com/pdfs/dataSheets/PD S_BP100_1011.pdf

[30] V. C. Bender, O. Iaronka, W. D. Vizzotto, M. A. D. Costa, R. N. do Prado, T. B. Marchesan, "Design Methodology for Light-Emitting Diode Systems by Considering an Electrothermal Model", IEEE Trans. on Electron Devices, vol. 60, pp. 3799-3806, Nov. 2013.

[31] V. C. Bender, I. Odirlan, W. D. Vizzotto, M. A. DallaCosta, R. N. Do Prado, T. B. Marchesan, "Metodologia de Projeto Eletrotérmico de LEDs aplicada ao Desenvolvimento de Sistemas de Iluminação", Eletrônica de Potência, vol. 18, pp. 991-1000, mar./mai., 2013.

\section{BIOGRAPHIES}

Odirlan Iaronka, was born in Casca, Brazil, in 1990. He received the B.S. degree in Electrical Engineering in 2014, in Federal University of Santa Maria (UFSM). In the period of 2009 to 2014 was a researcher in Electronic Ballast Research Group (GEDRE - UFSM). Currently working in the company WEG Electric Equipment, in the Development, Research and Innovation sector. His research interests include Numerical Simulations, Finite Element Method (FEM), Computational Fluids Dynamics (CFD), Thermal Management, LEDs, Power Electrical Transformers and Electromagnetism.

Vitor Cristiano Bender, was born in Panambi, Brazil in 1987. He received the B.S. degree in Electrical Engineering from the Regional University of the Northwest of Rio Grande do Sul in 2011 and Master Degree from Federal University of Santa Maria (UFSM) in 2012, is currently student in the Doctoral Course in (UFSM) working with Electronic Ballast Research Group (GEDRE). His research interests include lighting systems, light-emitting diodes (LEDs), organic light-emitting diodes (OLEDs), drivers for LEDs and OLEDs, thermal management and finite element analysis.

Tiago Bandeira Marchesan, was born in Santa Maria, Brazil, in 1980. He received the B.S. (with first-class honors) and Ph.D. degrees in electrical engineering from the Federal University of Santa Maria (UFSM), in 2003 and 2008, respectively. Since 2000, he has been a Researcher with the Electronic Ballast Research Group (GEDRE). Since 2011, he has been a Full Professor with the UFSM. His research interests include electronic ballasts, HID lamps, LEDs, dimming systems, and modeling and simulation of power converters. 